\title{
PROSES METAKOGNITIF MAHASISWA DALAM MENGERJAKAN SOAL HIGHER ORDER THINKING SKILLS DITINJAU DARI GAYA KOGNITIF
}

\author{
${ }^{1}$ Alifiani, ${ }^{2}$ Sikky El Walida \\ Universitas Islam Malang, Jalan MT Haryono 193 Malang, 0341 551932, Indonesia \\ e-mail: alifiani@unisma.ac.id
}

\begin{abstract}
Abstrak
Penelitian ini bertujuan untuk mendeskripsikan proses metakognitif mahasiswa dalam mengerjakan soal HOTS (Higher Order Thinking Skill) terkait materi aplikasi turunan peubah banyak, khususnya masalah ekstrim (maksimum-minimum) dalam mata kuliah Kalkulus Lanjut ditinjau dari gaya kognitifnya, yaitu Field Independence (FI), Field Dependence (FD), dan Field Neutral (FN). Sesuai dengan tujuan penelitian, pendekatan yang digunakan dalam penelitian ini adalah pendekatan kualitatif dengan jenis deskriptif eksploratif. Instrumen yang digunakan adalah peneliti sebagai instrumen utama, lembar soal, angket analisis gaya kognitif, dan alat rekam. Subjek penelitian terdiri dari 3 orang mahasiswa Pendidikan Matematika Semester 3 di salah satu Perguruan Tinggi di Kota Malang yang dipilih dengan teknik purposive sampling. Hasil dari penelitian ini adalah individu FI memiliki proses metakognitif yang lebih baik saat mengerjakan soal HOTS dibandingkan individu FD dan FN. FI melakukan metacognitive evaluation untuk memerika jawaban meski tidak menemui kendala atau kesalahan sedangkan individu FD dan FN baru melakukan metacognitive evaluation dalam memeriksa kembali jawaban ketika sadar bahwa ada kesalahan yang dilakukan. Jadi dapat disimpulkan bahwa individu FI memiliki proses metakognitif yang lebih baik saat mengerjakan soal HOTS dibandingkan individu FD dan FN.
\end{abstract}

Kata Kunci: Proses metakognitif, Soal HOTS, Field Independence, Field Dependence, Field Neutral

\begin{abstract}
This study aims to describe the metacognitive processes of students in solving HOTS (Higher Order Thinking Skill) problem related to the application of multivariable derivatives, especially about extreme problems (maximum-minimum) in Advanced Calculus courses in terms of cognitive style, namely Field Independence (FI), Field Dependence (FD), and Field Neutral (FN). In accordance with the objectives of the study, the approach used in this study was a qualitative approach with a descriptive exploratory type. The instrument used was the researcher as the main instrument, question sheets, cognitive style analysis questionnaires, and recording tools. The research subjects consisted of three $3^{\text {rd }}$ semester Mathematics Education Department students from one of University in Malang by purposive sampling technique. The results of this study are that FI has a better metacognitive process when working on HOTS problems than FD and FN individuals. FI conducts metacognitive evaluating to check answers even though she does not encounter any obstacles or errors while Individual FD and FN only do metacognitive evaluating in re-checking answers when they realize that an error has been made. So it can be concluded that FI individuals have a better metacognitive process when working on HOTS problems than FD and FN individuals.
\end{abstract}

Keywords: Metacognitive process, HOTS problem, Field Independence, Field Dependence, Field Neutral

\section{PENDAHULUAN}

Dalam menghadapi pesatnya kemajuan IPTEK dan arus globalisasi pada abad 21, diperlukan sumber daya manusia (SDM) yang dapat mengembangkan kapasitas pengetahuan agar dapat memiliki kemampuan berpikir tingkat tinggi atau lebih dikenal dengan istilah Higher Order Thinking Skills (HOTS) (Miri, et al., 2007). HOTS merupakan salah satu komponen dari berpikir kritis dan kreatif (Heong, et al., 2011), di mana pada abad 21 berpikir kritis dibutuhkan dalam menganalisis situasi yang tidak familiar (Miri, et al., 2007) dan berpikir 
kreatif dibutuhkan dalam mendukung kemajuan ekonomi dan globalisasi (Heong, et al., 2012).

Oleh karena itu, HOTS merupakan aspek penting dalam dunia pendidikan, khususnya dalam pembelajaran abad 21 untuk memfasilitasi peserta didik maupun mahasiswa agar dapat menghadapi tuntutan perkembangan zaman di abad 21 (Heong, et al., 2011; Tanujaya, et al., 2017; Miri, et al., 2007).

Implementasi HOTS dalam pembelajaran matematika sangat esensial dalam rangka mengubah stigma masyarakat bahwa matematika itu menakutkan serta memberikan kesempatan untuk mengembangkan pemahaman, kemampuan berpikir kritis, dan kreativitas sehingga matematika menjadi mudah dan menyenangkan (Abdullah, et al., 2017). Implementasi HOTS dalam pembelajaran matematika menggunakan Taksonomi Bloom (Thompson, 2008). Kemampuan berpikir secara garis besar dapat dikelompokkan menjadi dua bagian yaitu lower-order thinking skills (LOTS), dan higher order thinking skills (HOTS) (Tanujaya, et al., 2017). LOTS hanya melibatkan 3 aspek terendah Taksonomi Bloom, yaitu knowledge, comprehension dan application, sementara HOTS sudah mencakup 3 aspek selanjutnya dari Taksonomi Bloom yaitu analyzing, synthesis, dan evaluation (Gambar 1).

\section{Bloom's Taxonomy}

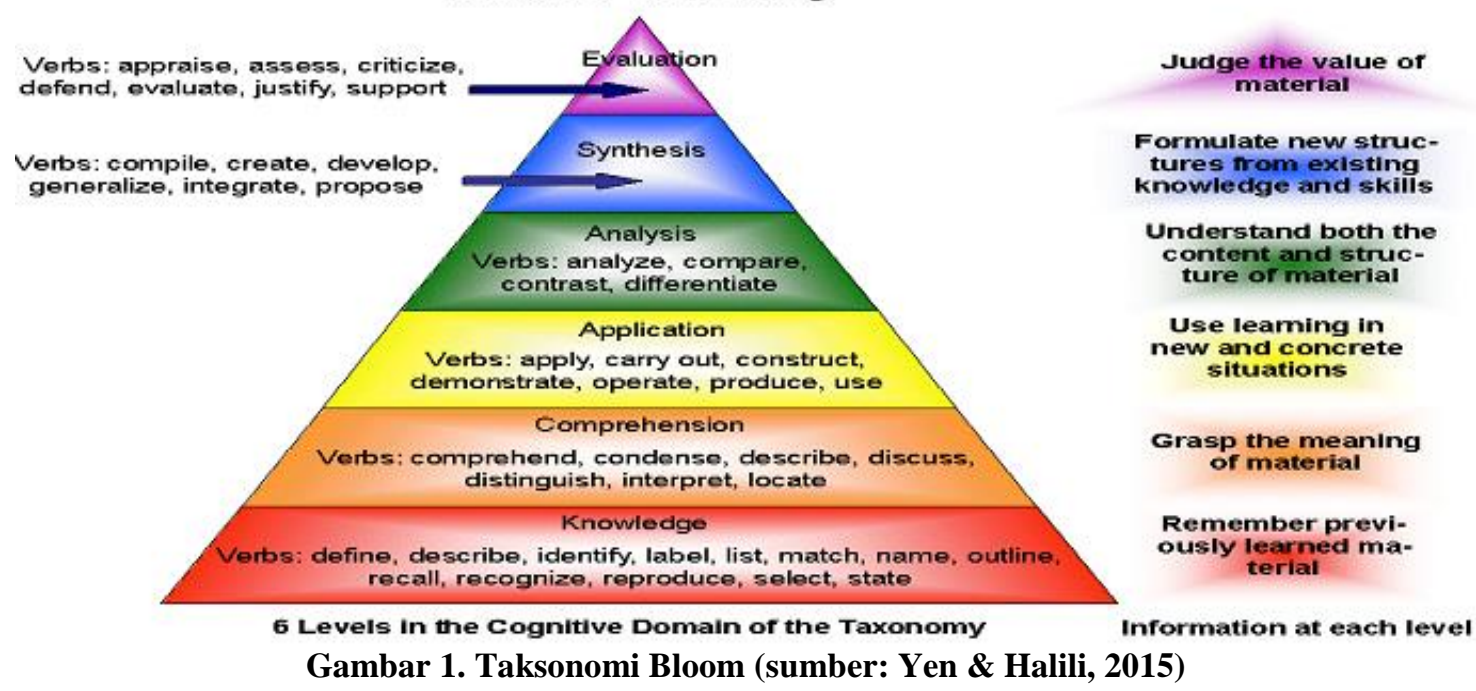

Dalam menerapkan keenam aspek Taksonomi Bloom saat mengerjakan soal HOTS diperlukan kemampuan dalam mengelola setiap proses supaya terstruktur dan menemukan hasil yang tepat. Kemampuan tersebut berupa self-regulation atau regulasi diri, di mana selfregulation adalah kemampuan untuk mengontrol dan memandu proses berpikir mahasiswa dalam mencapai tujuan atau hasil (Vula, et al., 2017). Self-regulation meliputi proses berpikir yang mengarahkan mahasiswa untuk memahami masalah, memonitor atau mengevaluasi proses, serta mencapai tujuan atau menemukan hasil. Kemampuan-kemampuan tersebut selanjutnya dapat dirangkum dalam satu payung yang disebut metakognitif (Wilson \& 
Conyers, 2016) di mana hal tersebut dapat membuat mahasiswa tetap berpikir sesuai jalur atau "right on the track" sehingga dapat meningkatkan hasil pemecahan masalah (Huda, et al., 2016).

Magiera dan Zawojewski (2011) mengklasifikasikan metakognitif menjadi 3 komponen, yaitu sebagai: 1) metacognitive awareness merupakan kesadaran untuk memikirkan posisi pengetahuannya, strategi yang digunakan, hubungan pengetahuan dan strategi untuk menyelesaikan tugas. 2) metacognitive regulation merupakan kesadaran untuk merefleksi kembali apa yang telah dipikirkan sebelumnya dalam rangka membuat perencanaan, menentukan tujuan. 3) metacognitive evaluation merupakan kesadaran individu untuk mempertimbangkan keterbatasan pengetahuannya, strategi yang ditentukan, dan kualitas hasil.

Metakognitif tidak selalu berjalan lancar tanpa kendala, apabila ada kegagalan pada proses metakognisi maka dapat mengarah pada kegagalan metakognitif atau dikenal dengan metacognitive failure (MF) (Huda, et al., 2016; Stillman, 2011). Salah satu yang menyebabkan MF sebagai kesalahan dalam proses metacognitive evaluation adalah dalam mempertimbangkan keterbatasan proses berpikir, keefektifan strategi yang dipilih, kesulitan masalah yang dihadapi, dan kemampuan memprediksi hasil berdasarkan strategi atau kemampuan di mana proses metakognitif bisa terjadi satu atau lebih MF (Huda, et al., 2018).

Berkaitan dengan aktivitas metakognitif dan kegagalan metakognitif ada istilah "red flag" yang mengindikasikan perlunya seseorang untuk menghentikan atau memeriksa ulang proses penyelesaian masalah (Stillman, 2011). Selanjutnya Stillman (2011) membagi tipe MF menjadi tiga, yaitu: (1) Metacognitive Blindness adalah kegagalan metakognitif ketika seorang individu melakukan kesalahan pada proses pengerjaan tugas dan tidak menyadari "red flag". (2) Mirage metacognitive adalah kegagalan metakognitif ketika seorang individu tidak melakukan kesalahan tetapi merasa ada "red flag" padahal tidak ada. (3) Vandalism metacognitive adalah kegagalan metakognitif yang ditandai dengan perbedaan konsep dan konteks masalah saat merespons "red flag".

Metakognitif merupakan kemampuan berpikir individual yang unik, berbeda antar individu dan memiliki peranan penting dalam proses berpikir tiap individu (Amin \& Sukestiyarno, 2015). Dapat dikatakan masing-masing individu memiliki gaya kognitif yang berbeda antara satu dengan lainnya. Gaya kognitif merujuk pada konsistensi proses berpikir, cara pandang, atau strategi pendekatan analitik dan holistik seorang individu yang biasa digunakan dalam memperoleh dan mengolah informasi sebagai usaha memecahkan masalah (Kozhevnikov, et al., 2014; Simuth \& Schuller, 2015; Salvisberg, 2005). Walaupun masing- 
masing individu memiliki pola pikir, cara pandang, bahkan pendekatan yang mirip, namun masing-masing individu memproses informasi dengan caranya masing-masing tergantung pada kemampuan kognitifnya (Salvisberg, 2005). Perbedaan gaya koginitif individu juga dapat dipengaruhi oleh bagaimana cara masing-masing individu dalam menanggapi kondisi lingkungkan (Oh \& Lim, 2005).

Meski setiap individu memiliki gaya kognitif yang berbeda-beda, namun gaya kognitif dapat dikelompokkan menjadi 3 kelompok besar yaitu field independent (FI), field dependent (FD), dan field neutral (FN). Individu dengan FI cenderung melihat lingkungan secara analitis, mengklasifikasi hal-hal berdasar kriteria tertentu, sementara individu dengan FD cenderung untuk memahami hal-hal dengan cara yang relatif global, mudah dipengaruhi oleh lingkungan sekitar atau konteks (Oh \& Lim, 2005; Salvisberg, 2005). Berbeda dengan individu FD yang lebih sosial, empatik dan tanggap terhadap orang lain, lebih baik dalam hal keterampilan komunikasi. Sedangkan individu FN lebih fleksibel dalam menentukan gaya kognitifnya (Kozhevnikov, et al., 2014). Dalam pandangan individu FN gaya kognitif yang terbaik adalah "no style", yaitu individu dapat memilih gaya yang paling tepat sesuai dengan kondisi yang dihadapi.

Permasalahan yang ada dalam dunia pendidikan saat ini adalah proses berpikir atau lebih khusus proses metakognitif seringkali tidak diperhatikan pada proses pembelajaran matematika termasuk saat menyusun perencanaan pembelajaran maupun saat menyusun instrumen evaluasi. Padahal metakognitif memiliki peranan penting dalam pembelajaran matematika (In'am, et al., 2012).

Penelitian ini bertujuan untuk mendeskripsikan bagaimana proses metakognitif mahasiswa dalam mengerjakan soal HOTS ditinjau dari gaya kognitifnya. Berbeda dengan Ngilawajan (2013), Mawardi, Yanti, dan Arrifadah (2020) yang meninjau dari gaya kognitif FI dan FD, sementara dalam penelitian ini, peneliti bertujuan mendeskripsikan proses metakognitif mahasiswa termasuk kegagalan metakognitif yang mungkin terjadi ditinjau dari gaya kognitif FI, FD, dan FN dalam mengerjakan soal HOTS.

\section{METODE PENELITIAN}

Pendekatan penelitian yang digunakan dalam penelitian ini adalah pendekatan kualitatif. Penelitian ini bertujuan untuk mendeskripsikan metakognitif mahasiswa dalam menyelesaikan soal HOTS ditinjau dari gaya kognitif, yaitu FD, FI, dan FN terkait materi aplikasi turunan peubah banyak. Data yang diperoleh dalam penelitian ini adalah data verbal yang berupa 
ungkapan mahasiswa ketika mahasiswa menyelesaikan soal HOTS. Jenis penelitian ini dapat dikategorikan sebagai penelitian deskriptif eksploratif, yaitu mendeskripsikan hasil eksplorasi metakognitif mahasiswa dalam mengerjakan soal HOTS. Dikatakan penelitian deskriptif eksploratif karena data yang dikumpulkan merupakan data verbal (Subanji, 2007).

\section{Lokasi dan Subjek Penelitian}

Penelitian ini dilaksanakan di Program Studi Pendidikan Matematika pada salah satu Perguruan Tinggi di Kota Malang Semester Gasal 2019/2020. Tenik pemilihan subjek dalam penelitian ini adalah teknik purposive sampling di mana subjek penelitian dipilih berdasarkan gaya kognitif mahasiswa. Subjek penelitian dipilih 3 dari 29 mahasiswa Prodi Pendidikan Matematika yang dianalisis, yaitu 1 mahasiswa dengan gaya kognitif FD, 1 mahasiswa dengan gaya kognitif FI, dan 1 mahasiswa dengan gaya kognitif FN. Proses pengklasifikasian gaya kognitif mahasiswa diadaptasi dari Alifiani dan Walida (2019). Pertimbangan kemampuan komunikasi mahasiswa digunakan untuk dapat menggali banyak informasi dari subjek. Kemampuan komunikasi dilihat berdasarkan proses wawancara. Subjek juga harus memiliki kemampuan matematis yang sama, sehingga perbedaan proses metakognitif yang terjadi nantinya bisa diasumsikan akibat adanya perbedaan gaya kognitif. Kemampuan matematis dilihat dari data KAM (Kemampuan Awal Mahasiswa) yang diambil dari nilai kuis.

\section{Instrumen Penelitian}

Instrumen penelitian yang digunakan untuk memperoleh data dalam penelitian ini di antaranya adalah peneliti sebagai instrumen utama, lembar soal, angket analisis gaya kognitif, dan alat rekam. Peneliti sebagai instrumen berperan sebagai perencana, pengumpul data, penganalisis data, penafsir data, dan akhirnya menjadi pelapor hasil penelitian. Sebagai pengumpul data, peneliti melakukan wawancara kepada mahasiswa. Wawancara kepada mahasiswa dilakukan untuk mengetahui proses metakognitif mahasiswa saat menyelesaikan soal HOTS. Dalam proses wawancara, mahasiswa diminta menyampaikan apa yang dipikirkan saat memecahkan masalah secara lisan (Think Alouds).

Angket analisis gaya kognitif bertujuan untuk mengidentifikasi gaya kognitif mahasiswa Pendidikan Matematika sebagai calon subjek penelitian (Alifiani \& Walida, 2019). Lembar soal berisi 1 soal terkait materi ekstrim (maksimum-minimum) yang terlebih dahulu divalidasi ahli sebelum digunakan. Validasi dilakukan agar soal yang digunakan benar-benar valid sebagai Soal HOTS, yaitu soal yang mengukur kemampuan pada aspek menganalisis, 
mengevaluasi, dan mengkreasi (Fanani, 2018; Suryapuspitarini, Wardono, Kartono, 2018). Adapun soal yang dimaksud adalah sebagai berikut.

Tentukan titik koordinat pada permukaan $x^{2}+y^{2}+z^{2}=4$ yang terdekat dan terjauh dari titik $(3,1,-1)$

\section{Teknik Analisis Data}

Proses analisis dilakukan untuk menganalisis metakognitif siswa dalam mengerjakan soal HOTS dilakukan dengan langkah-langkah: (1) mentraskrip data verbal yang terkumpul, (2) menelaah seluruh data yang tersedia dari berbagai sumber, yaitu dari hasil think alouds, wawancara, hasil rekaman video dan rekaman suara, serta hasil pekerjaan mahasiswa, (3) mengadakan reduksi data dengan membuat abstraksi, yaitu usaha membuat rangkuman yang inti, proses, dan pernyataan-pernyataan yang perlu dijaga, (4) memetakan metakognitif subjek penelitian, (5) analisis metakognitif mahasiswa beserta kegagalan metakognitif (MF) yang terjadi.

\section{HASIL DAN PEMBAHASAN}

Berdasarkan pertimbangan yang telah dilakukan dalam rangka memilih subjek penelitian, dari 29 mahasiswa Pendidikan Matematika yang dianalisis gaya kognitifnya dipilih 3 orang subjek penelitian, yaitu S2 (FI), S18 (FD), dan S23 (FN). Ketiga subjek tersebut dipilih karena: (1) mewakili masing-masing jenis gaya kognitif, (2) memiliki kemampuan komunikasi yang baik, sehingga dipandang kaya akan data, (3) ketiga subjek memiliki kemampuan matematis yang sama, sehingga perbedaan yang terjadi nantinya bisa diasumsikan akibat adanya perbedaan gaya kognitif.

\section{Proses Metakognitif S2 (FI)}

Mahasiswa dengan gaya kognitif Field Independence (FI) diwakili oleh Subjek 2 (S2). Dalam mengerjakan soal HOTS, S2 sudah melibatkan proses metakognitif dengan baik. Diawali dengan metacognitive awareness saat mahasiswa menyadari untuk mengidentifikasi soal dan kemampuannya terlebih dahulu. S2 juga melakukan analisis mendalam dalam memahami soal dengan membuat grafik fungsi untuk mengidentifikasi jenis soal. Individu FI cenderung selalu melibatkan analisis dalam menguasai tugas (Oh \& Lim, 2005; Salvisberg, 2005). Berikut kutipan wawancara dengan S2.

P (peneliti) : "Saat membaca soal tersebut apa yang pertama kali terlintas dalam pikiran Anda?" S2 : "Awalnya saya membaca sekilas soal tersebut terkait dengan maksimumminimum begitu, Bu. Awalnya saya merasa bisa karena sudah pernah 
mempelajarinya. Tetapi kemudian setelah saya pikirkan lagi soal tersebut terkait dengan ekstrim bersyarat." (awareness)

P : "Kenapa Anda bisa berpikir bahwa soal tersebut merupakan soal ekstrim bersyarat?"

S2 : "Iya bu, setelah saya baca kemudian saya mencoba menggambar grafik $x^{2}+y^{2}+z^{2}=4$ ini. Ternyata membentuk bola. Nah berarti, soal ini meminta kita mencari jarak titik koordinat $(3,1,-1)$ ini ke permukaan bola. Sehingga tujuannya mencari jarak, selanjutnya rumus jarak menjadi fungsi tujuan dan syaratnya harus pada permukaan bola jaraknya tadi. Jadi $x^{2}+y^{2}+z^{2}=4$ ini menjadi fungsi kendalanya. Karena ada fungsi kendala dan tujuan maka ini ekstrim bersyarat." (awareness)

Selanjutnya, S2 juga melakukan proses metacognitive evaluation saat S2 mempertimbangkan berbagai strategi yang dapat digunakan dengan memperhatikan kelebihan dan kekurangan masing-masing strategi dan akhirnya melakukan metacognitive regulation saat menentukan strategi yang paling tepat dalam menyelesaikan tugas. Berikut kutipan wawancara dengan S2.

$\mathrm{P}$

: "Setelah mengetahui bahwa soal tersebut merupakan ekstrim bersyarat apa yang Anda pikirkan? Masih merasa bisa, atau justru sebaliknya?"

S2 : "InsyaAllah bisa bu, karena sudah pernah belajar juga. Di situ, Saya langsung memikirkan cara menyelesaikannya bu, untuk ekstrim bersayarat bisa pakai cara eksplisit, implisit, atau Lagrange. Lalu saya berpikir untuk menggunakan cara Lagrange saja, karena menurut saya cara Lagrange itu relative mudah untuk semua jenis. Kalau eksplisit dan implisit untuk soal tertentu kadang agak rumit bu kadang malah ga ketemu hasilnya, ga semua soal mudah pakai eksplisit dan implisit ini." (evaluation)

"Jadi saya memutuskan memutuskan untuk pakai cara Lagrange yang lebih aman dan saya bisa lebih mudah nanti mengerjakannya." (regulation)

Proses penyelesaian soal HOTS S2 juga sangat rapi dan sistematis sesuai karakteristik FI (Oh \& Lim, 2005). S2 juga memperhatikan detail dan berusaha menguasai tugas dengan baik sesuai karakteristik FI (Salvisberg, 2005). Dalam menyelesaikan tugas, S2 juga melakukan metacognitive evaluation dalam rangka memeriksa kembali kebenaran pekerjaan sehingga jawaban S2 benar. 


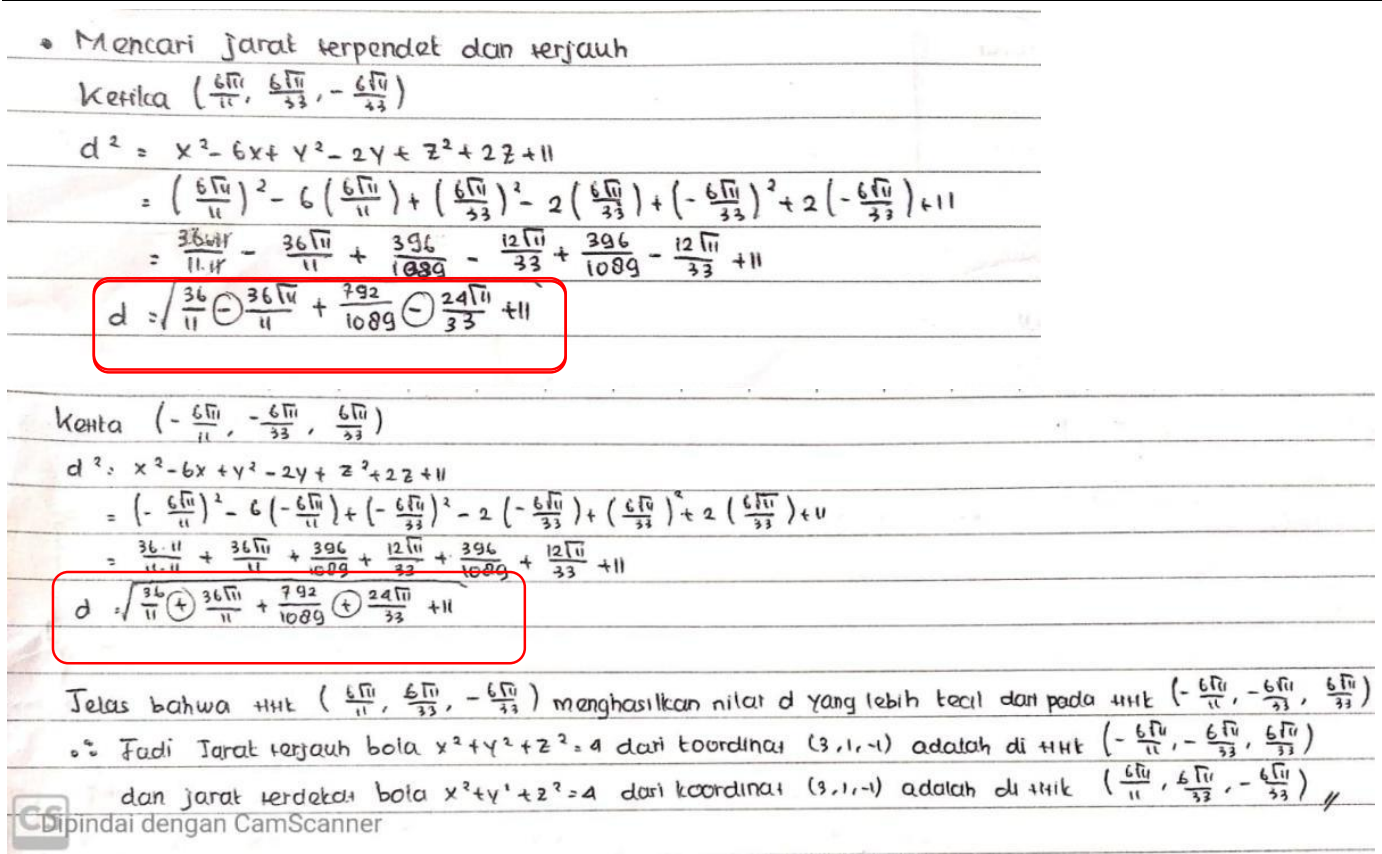

\section{Gambar 2. Jawaban S2}

Dari Gambar 2 dapat dilihat bahwa S2 melingkari tanda positif dan negatif. Hal tersebut dilakukan S2 untuk menentukan mana jarak yang lebih kecil dan lebih besar tanpa harus menghitung jarak pastinya karena memang soal tidak menanyakan jarak terpendek dan terjauh, tetapi hanya menanyakan titik koordinatnya saja. Jawaban akhir S2 sudah benar, S2 juga sudah yakin jawabannya benar karena merasa sudah memeriksa kembali.

Jadi, dapat dikatakan S2 sangat "well organized" dalam menyelesaikan tugas sesuai karakteristik FI (Oh \& Lim, 2005) dan sudah melibatkan proses metakognitif dengan baik sesuai pendapat Magiera dan Zawojewski (2011). Dalam penelitian ini diketahui bahwa S2 (FI) selalu melibatkan analisis sebelum mengambil keputusan dan mengevaluasi hasil pemikirannya.

\section{Proses Metakognitif S18 (FD)}

Mahasiswa dengan gaya kognitif Field Dependence (FD) diwakili oleh Subjek 18 (S18). S18 juga sudah melakukan proses metacognitive awareness untuk mengidentifikasi soal dan mengenali pengetahuan yang dimiliki, meski hasil identifikasi S18 tidak sepenuhnya tepat. S18 melihat soal secara global bahwa soal tersebut terkait dengan maksimum-minimum tetapi S18 tidak melakukan analisis lebih lanjut bahwa sesungguhnya soal tersebut bukan sekedar masalah ekstrim (maksimum-minimum) tetapi merupakan ekstrim bersyarat. Hal ini sesuai dengan ciriciri individu FD bahwa individu FD cenderung melihat segala sesuatu secara global (Oh \& Lim, 2005). Namun S18 tidak melakukan metacognitive evaluation karena S18 hanya dapat memikirkan satu cara yaitu rumus D saja. S18 langsung pada metacognitive regulation, yaitu Proses metakognitif mahasiswa dalam mengerjakan soal higher order thinking skills ... 
memikirkan langkah-langkah selanjutnya sesuai dengan pengetahuan yang dimiliki yaitu rumus D. Namun kesalahan kembali terjadi seperti yang terlihat pada Gambar 3.

$\begin{array}{ll}v^{2}+y^{2}+z^{2}-4 & =0 \\ f_{x x}=2 & 0=f_{x x} \cdot f_{y y}-f_{x y^{2}} \\ f_{x y}=0 & =2 \cdot 2-(0)^{2} \\ f_{y y}=2 & =4>0 \text { mingsimum lokal } \\ \text { CEijindai dengan Camscanner } & \end{array}$

Gambar 3. Jawaban S18

S18 langsung mencari turunan parsial fungsi secara eksplisit, padahal fungsi tersebut masih implisit yang sebenarnya harus dieksplisitkan terlebih dahulu, setelah itu baru dicari turunan parsialnya. Akibatnya di sini muncul "red flag" yang membuat pekerjaan S18 berhenti dan membuat S18 kembali mengevaluasi jawabannya seperti yang tercermin dalam cuplikan wawancara berikut.

P : :Kenapa tidak dilanjutkan?"

S18 : "Macet bu."

$\mathrm{P} \quad$ : "Kenapa macet?"

S18 : "Karena yang ditanya nilai maksimum dan nilai minimum, tetapi saat saya masukkan ke dalam rumus hanya ketemu nilai minimum. Saya bingung nilai maksimumnya nanti didapat dari mana."

P : :Apa kamu tidak melakukan analisis lebih lanjut?"

S18 : "Sudah saya coba mengkoreksi kembali jawaban saya, tapi saya merasa sudah benar bu."

P : "Apa kamu percaya diri dengan jawabanmu?"

S18 : "Tidak bu, karena hasilnya tidak ketemu."

$\mathrm{P} \quad$ : "Apa kamu tidak mencoba menganalisis kembali soalnya?"

S18 : "Tidak bu, kan sudah jelas soal meminta untuk mencari nilai maksimum dan nilai minimum."

P : :Apa tidak mencoba cara lain?"

S18 : "Kalau mencari nilai maksimum dan minimum kan memang memakai rumus D ya bu?"

P : :Lalu kenapa tidak ketemu?"

S18 : "Saya juga tidak tahu $B u$, nanti akan saya coba diskusikan dengan teman saya."

Berdasarkan hasil wawancara dapat diketahui bahwa setelah munculnya red flag, S18 tidak dapat menemukan letak kesalahannya. Sampai pada akhir wawancara, diketahui bahwa S18 perlu berdiskusi dengan teman (orang lain) untuk membantunya. Hal ini sesuai dengan pendapat Oh dan Lim (2005) serta Salvisberg (2005) bahwa individu FD cenderung perlu berdiskusi dengan orang lain untuk membantunya dalam menyelesaikan masalah. Meski demikian S18 tidak dapat dikategorikan mengalami MF (Metacognitive Failure) karena tidak memenuhi 3 tipe MF, yaitu (1) Bukan merupakan metacognitive blindness karena S18 
menyadari adanya red flag, (2) bukan merupakan mirage karena memang sesungguhnya jawaban S18 salah, (3) bukan merupakan vandalism, karena setelah red flag S18 tidak mengubah apapun.

Jadi, dapat dikatakan S18 selaku individu FD cenderung memandang sesuatu secara global dan membutuhkan bantuan orang lain ketika menghadapi masalah. Hal ini sesuai dengan karakteristik individu FD yang diungkapkan oleh Oh dan Lim (2005) serta Salvisberg (2005). Dalam proses metakognitif, pada awalnya S18 sudah melakukan metacognitive awareness dalam mengidentifikasi soal dan memikirkan pengetahuan yang dimiliki. Meski hasil identifikasinya masih kurang tepat, S18 juga melakukan metacognitive regulation dalam memikirkan langkah-langkah pengerjaan, meski pada prosesnya juga menemukan kendala karena adanya kesalahan langkah pengerjaan. Pada akhirnya S18 juga melakukan metacognitive evaluation ketika menemui kesalahan yang membuat macet atau red flag. Namun demikian, S18 belum dapat dikategorikan mengalami MF karena tidak memenuhi ketiga tipe MF.

\section{Proses Metakognitif S23 (FN)}

Mahasiswa dengan gaya kognitif Field Neutral (FN) diwakili oleh Subjek 23 (S23). Pada awalnya, S23 sudah melakukan metacognitive awareness dalam mengidentifikasi soal. Di sini S23 juga sudah melakukan analisis dalam menentukan jenis soal. S23 melakukan analisis dengan melihat bentuk umum fungsi. Hal ini menandakan S23 memiliki karakter FI yang diungkapkan oleh Oh dan Lim (2005) serta Salvisberg (2005) bahwa individu FI cenderung selalu melibatkan analisis dalam menguasai tugas. Meski demikian S23 juga menunjukkan keraguan dan berusaha menanyakan kebenaran jawaban kepada peneliti seperti terecermin dalam cuplikan wawancara berikut.

S23 : "Karena ini ada fungsi tujuannya yaitu untuk memaksimalkan dan meminimumkan jarak ke permukaan bola. Jadi nanti rumus permukaan bolanya ini sebagai fungsi kendalanya."

P : : "Kenapa kamu bisa menyimpulkan bahwa permukaannya merupakan bola? Apa kamu gambar grafiknya dulu atau bagaimana?"

S23 : "Tidak bu, saya hanya melihat bentuknya saja, sesuai dengan bentuk umumnya bola bu. Jadi ya saya menyimpulkan itu bola, tanpa menggambar. (menunjukkan keraguan, dan berpikir sejenak) Salah ya bu?"

P : : "Tidak kok."

Dalam petikan wawancara tersebut terlihat bahwa S23 menunjukkan keraguan atas jawabannya dan bertanya kepada peneliti “Salah ya bu?” Hal ini menunjukkan karakteristik 
FD di mana S23 cenderung menanyakan atau meminta pertimbangan orang lain saat menemui kendala (Oh \& Lim, 2005)

Selanjutnya, S23 juga melakukan metacognitive evaluation dalam mempertimbangkan strategi yang paling tepat sesuai dengan kemampuan yang dimilikinya dan melakukan metacognitive regulation dalam memutuskan strategi yang paling tepat sesuai kemampuan yang dimilikinya. Dalam hal ini S23 memilih menggunakan metode eksplisit, dan menyelesaikan sesuai langkah-langkah metode eksplisit. Di awal pengerjaan S23 mengerjakan dengan tepat sesuai langkah. S23 juga memberi tanda-tanda khusus pada bagian yang dianggap penting dan memberi nomor yang kemudian dilingkari sebagaimana yang terlihat pada Gambar 4. Hal ini juga menunjukkan karakteristik FI yaitu memperhatikan detail (Salvisberg, 2005).

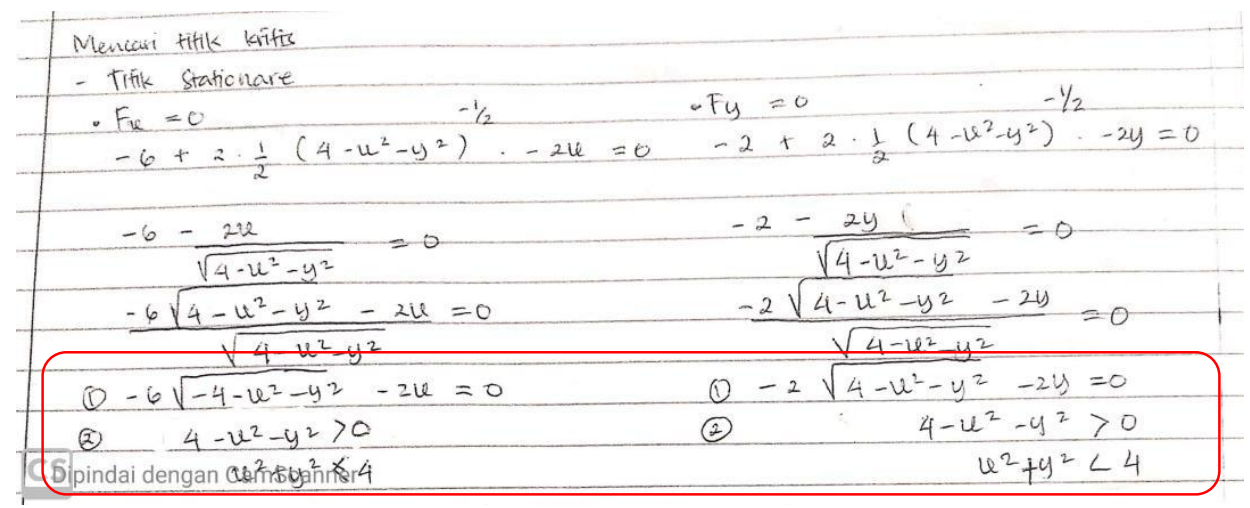

Gambar 4. S23 menentukan domain titik kritis dan memberi tanda

Namun, karena sebenarnya S23 ini bukan sepenuhnya individu FI melainkan FN, S23 kurang teliti dalam memperhatikan detail yang sudah ditandainya sendiri. S23 melakukan kesalahan dalam menentukan titik kritis karena tidak memperhatikan domainnya seperti terlihat pada Gambar 5 berakibat jawaban akhir salah yang terlihat pada Gambar 6.

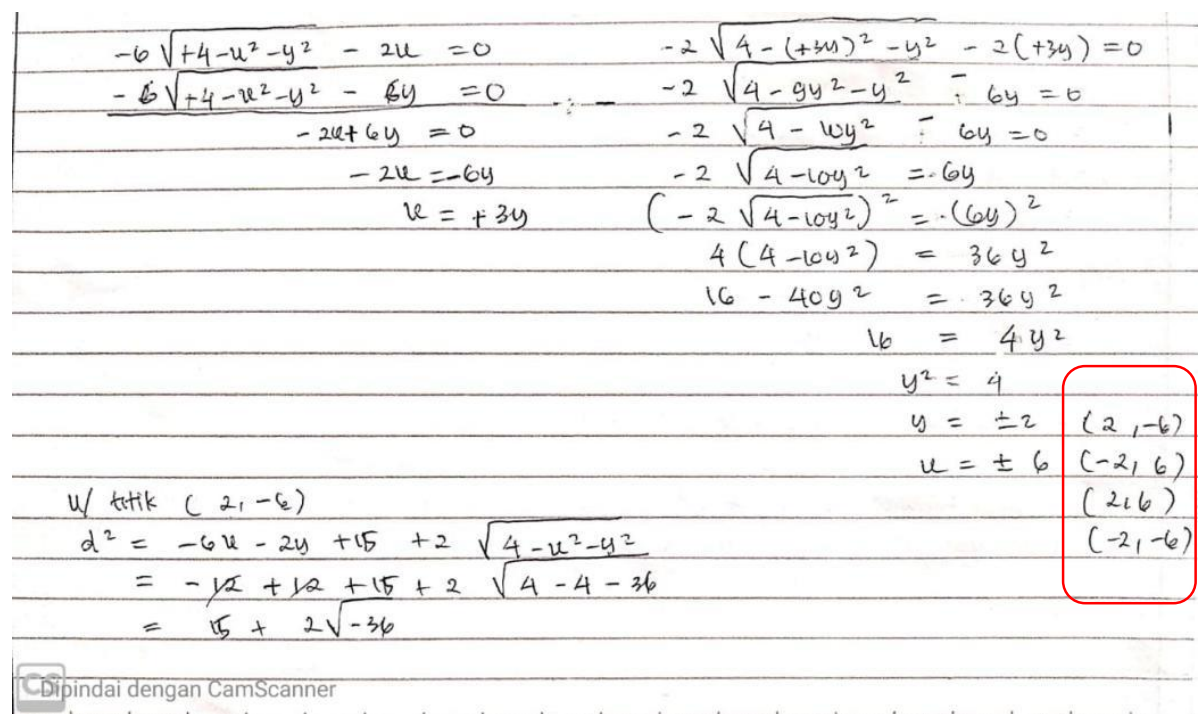

Gambar 5. S23 salah dalam menentukan titik kritis 


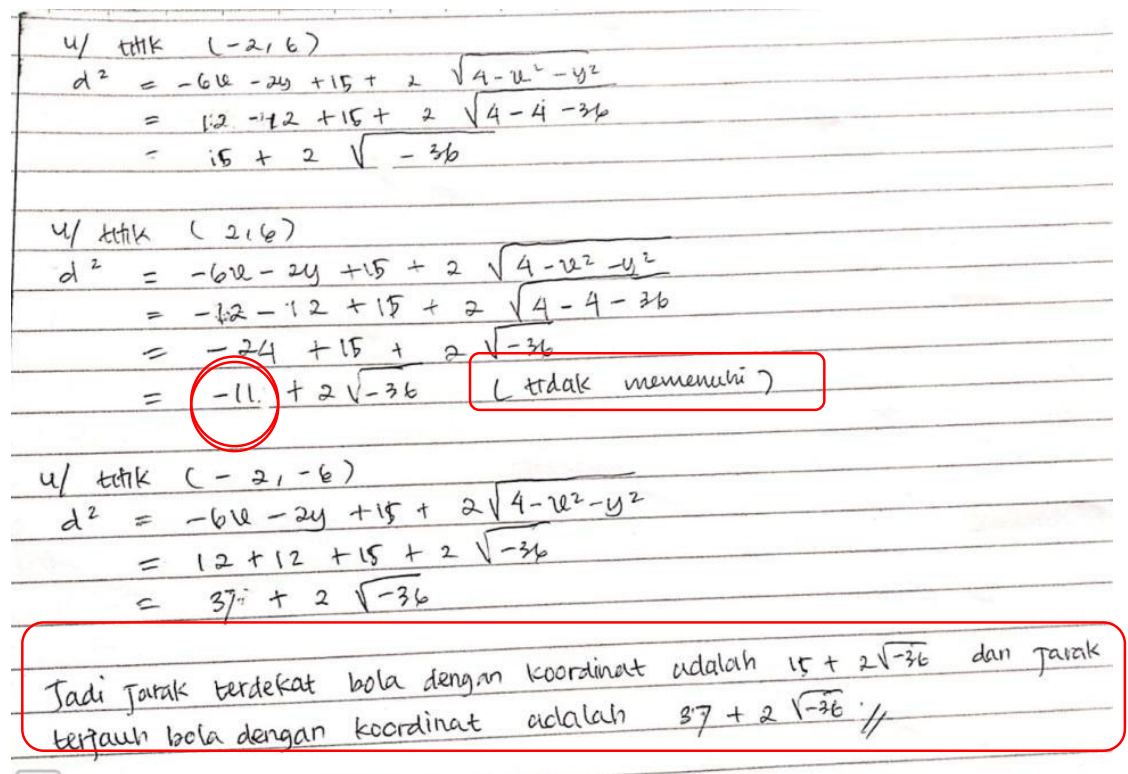

Gambar 6. Jawaban akhir S23 salah

Akibatnya menghasilkan jawaban akhir yang salah pula. Pada awalnya, S23 tidak menyadari kesalahannya, namun setelah diberi pertanyaan pancingan dalam proses wawancara barulah S23 menyadarinya, seperti tercermin dalam cuplikan wawancara berikut ini.

P : "Apa Anda yakin dengan jawaban akhir Anda?"

S23 : "InsyaAllah, sudah benar Bu."

$\mathrm{P} \quad$ : "Apa sudah kamu periksa Kembali jawabanmu?"

S23 : "Belum sih bu, ya karena memang sepertinya sudah betul, jawabnnya ketemu."

P : "Coba jelaskan, kenapa ini tidak memenuhi sedang lainnya memenuhi?" (Gambar 6)

S23 : "Ya karena ini negative bu, kalau jarak kan tidak mungkin negatif."

$\mathrm{P} \quad$ : "Oh, coba perhatikan bilangan dalam akar? Kalau bilangan negatif dalam akar apa boleh untuk jarak?"

S23 : "Oiya ya bu. Salah saya..."

P : "Kira-kira salahnya mulai dari mana ini?"

S23 : (memeriksa kembali jawabannya dan menemukan kesalahannya) "Ini bu (Gambar 5 dan 6), saya tidak memperhatikan domainnya."

P : "Coba dibenarkan terlebih dahulu."

S23 : (mencoba mengerjakan dengan memperhatikan domain) "Kok malah ga ketemu ya bu titik kritisnya?"

P : "Kenapa seperti itu? Apa ada yang salah? Coba diperiksa kembali."

S23 : (berusaha memeriksa kembali) "Sepertinya strategi eksplisit kurang sesuai bu. Harus pakai strategi lain sepertinya."

P : "Silahkan dicoba kalau begitu"

S23 : (mencoba dengan cara Lagrange dan sesekali bertanya pada S2 dalam mengerjakan)

Sekali lagi terlihat bagaimana S23 menunjukkan karakteristik FD di mana S23 membutuhkan pengaruh lingkungan untuk menyadari kesalahannya dan membutuhkan bantuan orang lain, yaitu bertanya pada S2 ketika menemui kendala saat mengerjakan dengan 
cara Lagrange (Oh \& Lim, 2005). Jadi dapat disimpulkan bahwa individu FN memiliki karakteristik FI dan FD di mana masing-masing karakter tersebut terlihat saat S23 mengerjakan soal HOTS. Individu FN lebih fleksibel dalam menentukan gaya kognitifnya, FN dikaterogikan berada di antara FI dan FD (Kozhevnikov, et al., 2014).

S23 juga sudah melakukan proses metakognitif, yaitu metacognitive awareness, evaluation, dan regulation. Namun, S23 sempat tidak menyadari adanya kesalahan yang membuatnya behenti dan berpikir kembali (red flag). Oleh karena itu, di sini dipandang bahwa S23 mengalami metacognitive failure (MF). Proses metakognitif tidak selalu berjalan lancar tanpa kendala, apabila ada kegagalan pada proses metakognisi maka dapat mengarah pada kegagalan metakognitif atau dikenal dengan metacognitive failure (Huda, et al., 2016).

Kegagalan metakognitif yang terjadi pada S23 dapat dikategorikan sebagai metacognitive blindness karena S23 tidak menyadari adanya red flag. Hal ini dapat disebabkan karena adanya kesalahan dalam menentukan strategi dalam proses metacognitive evaluation (Huda, et al., 2018). Strategi eksplisit memang tidak selalu mudah diterapkan untuk setiap soal. Ada soal yang lebih mudah dikerjakan dengan cara eksplisit, dan beberapa soal lainnya tidak. Hal ini sudah dipertimbangkan S2, tetapi S23 tidak mempertimbangkan hal tersebut.

\section{SIMPULAN DAN SARAN}

\section{Simpulan}

S2 (Individu FI) melibatkan analisis, memperhatikan detail, dan sangat "well organized" dalam menyelesaikan soal HOTS. FI sudah melibatkan proses metakognitif, yaitu metacognitive awareness, evaluation, dan regulation dengan baik dalam menyelesaikan soal HOTS. FI tidak membutuhkan keterlibatan orang lain dalam mengerjakan sampai menghasilkan jawaban benar. S18 (Individu FD) memandang soal HOTS secara global dan tidak melibatkan analisis. FD sudah melibatkan proses metakognitif, yaitu metacognitive awareness, dan regulation. S18 awalnya tidak melakukan metacognitive evaluation, tetapi saat mengalami "red flag" S18 melakukan metacognitive evaluation dalam memeriksa kembali jawabannya. FD membutuhkan keterlibatan orang lain untuk menghasilkan jawaban benar saat menyelesaikan soal HOTS. S23 (Individu FN) menunjukkan karakteristik FI dalam hal melibatkan analisis dan menunjukkan karakteristik FD saat membutuhkan keterlibatan orang lain dalam menyelesaikan soal HOTS. S23 sebenarnya sudah melakukan proses metacognitive awareness, evaluation, dan regulation dalam rangka mengidentifikasi soal, strategi yang dapat digunakan, dan langkah-langkah pengerjaan sesuai strategi yang diplih. Namun pada prosesnya S23 mengalami MF karena salah dalam menentukan strategi. 
Berdasarkan beberapa hal yang ditemukan dalam penelitian ini, maka dapat disimpulkan bahwa individu FI memiliki proses metakognitif yang lebih baik saat mengerjakan soal HOTS dibandingkan individu FD dan FN. FI melakukan metacognitive evaluation untuk memerika jawaban meski tidak menemui kendala atau kesalahan yang terjadi sedangkan Individu FD dan FN baru melakukan metacognitive evaluation dalam memeriksa kembali jawaban ketika sadar bahwa ada kesalahan yang terjadi. Untuk kasus dalam penelitian ini, individu FD dipandang masih lebih baik daripada FN karena FD tidak mengalami metacognitive failure.

\section{Saran}

Penelitian ini memiliki beberapa kekurangan, di antaranya masih belum dapat menjawab beberapa pertanyaan berikut ini: 1) Apakah hanya individu FN yang selalu mengalami MF? 2) Apakah individu FI mungkin mengalami MF? 3) Apakah individu FD mungkin mengalami MF? 4) Apakah benar proses metakognitif FD selalu lebih baik daripada FN? Oleh karena itu disarankan bagi peneliti lain untuk dapat mengembangkan penelitian ini dengan fokus penelitian tersebut untuk menjawab pertanyaan-pertanyaan yang belum dapat diungkap dalam penelitian ini. Bagi peneliti lain juga diharapkan untuk mengembangkan penelitian ini dalam jenjang atau pun materi yang berbeda untuk mengetahui proses metakognitif peserta didik. Mengetahui proses metakognitif peserta didik penting dilakukan di antaranya adalah agar dapat menentukan model dan evaluasi pembelajaran yang tepat.

\section{DAFTAR PUSTAKA}

Abdullah, A.H., Mokhtar, M., Halim, N.D.A, Ali, D.F., Tahir, L.M., \& Kohar, UHA. (2017). Mathematics teachers' level of knowledge and practice on the implementation of higherorder thinking skills (HOTS). EURASIA Journal of Mathematics Science and Technology Education, 13(1), 3-17.

Alifiani, \&Walida, S.E. (2019). Gaya kognitif mahasiswa pendidikan matematika. Seminar Nasional Pendidikan dan Ilmu Matematika (SENANDIKA), Program Studi Pendidikan Matematika Universitas Islam Malang, Malang, 14 Desember 2019, pp. 1-9.

Amin, I. \& Sukestiyarno, Y.L. (2015). Analysis metacognitive skills on learning mathematics in high school. International Journal of Education and Research, 3(3), 213-222.

Fanani, M. Z. (2018). Strategi pengembangan soal higher order thinking skill (hots) dalam kurikulum 2013. Edudeena: Journal of Islamic Religious Education, 2(1), 57-76.

Huda, N., Subanji, Nusantara, T., Sutawidjaja, A., \& Rahardjo, S. (2016). University students' metacognitive failures in mathematical proving investigated based on the framework of 
assimilation and accommodation. Educational Research and Reviews, 11(12), 11191128 .

Huda, N., Subanji, Nusantara, T., Sutawidjaja, A., \& Rahardjo, S. (2018). The errors of metacognitive evaluation on metacognitive failure of students in mathematical problem solving. Journal of Physics: Conference Series, 1008, 1-10.

Heong, Y.M., Othman, B.W. Yunos, J.M., Kiong, T.T. Hassan, R., \& Mohamad, M.M. (2011). The level of Marzano higher order thinking skills among technical education students. International Journal of Social Science and Humanity, 1(2), 121-125.

Heong, Y.M., Yunosa, J. M., Othman, B.W., Hassan, R., Kiong, T.T, \& Mohamad, M.M. (2012). The needs analysis of learning higher order thinking skills for generating ideas. Procedia - Social and Behavioral Sciences, 59, 197-203.

In'am, A., Sa'ad, N., \& Ghani, S.A. (2012). A metacognitive approach to solving algebra problems. International Journal of Independent Research and Studies, 1(4), 162-173.

Kozhevnikov, M. Evans, \& C, Kosslyn, S.M. (2014). Cognitive style as environmentally sensitive individual differences in cognition: a modern synthesis and applications in education, business, and management. Psychological Science in the Public Interest, $15(1), 3-33$

Magiera, M.T., \& Zawojewski, J.S. (2011). Characterization of social-based and self-based contexts associated with students' awareness, evaluation, and regulation of their thinking during small-group mathematical modelling. Journal for Research in Mathematics Education, 42(5), 486-516.

Mawardi, A.V., Yanti, W.A., \& Arrifadah, Y. (2020). Analisis proses berpikir siswa dalam menyelesaikan soal hots ditinjau dari gaya kognitif. JRPM (Jurnal Review Pembelajaran Matematika), 5(1), 40-52.

Miri, B., David, B.C., \& Uri, Z. (2007). Purposely teaching for the promotion of higher-order thinking skills: A case of critical thinking. Research Science Education, 37, 353-369

Ngilawajan, D. A. (2013). Proses berpikir siswa sma dalam memecahkan masalah matematika materi turunan ditinjau dari gaya kognitif field independent dan field dependent. PEDAGOGIA: Jurnal Pendidikan, 2(1), 71-83.

Oh, E. \& Lim, D. (2005). Cross relationships between cognitive styles and learner variables in online learning environment. Journal of Interactive Online Learning, 4(1), 53-66.

Salvisberg, J. (2005). Cognitive style and learning strategies. IATEFL, February-March: 2-7. 
Simuth Jr, J. \& Schuller, I.S. (2015). The preferences of cognitive style among university students from various study fields. Procedia-Social and Behavioral Sciences, 191, 25372540

Stillman, G. (2011). Applying metacognitive knowledge and strategies in applications and modelling tasks at secondary school. In G. Kaiser, W. Blum, R.B. Ferri, G. Stillman, (Eds.), Trends in Teaching and Learning of Mathematical Modelling (p.p.165-180). Dordrecht, Heidelberg: Springer.

Subanji. (2007). Proses berpikir penalaran kovariasional pseudo dalam mengkonstruksi grafik fungsi kejadian dinamik berkebalikan. Disertasi tidak diterbitkan. Surabaya: Program Pascasarjana UNESA.

Suryapuspitarini, B. K., Wardono, Kartono. (2018). Analisis soal-soal matematika tipe higher order thinking skill (hots) pada kurikulum 2013 untuk mendukung kemampuan literasi siswa. PRISMA, Prosiding Seminar Nasional Matematika, 1, 876-884.

Tanujaya, B., Mumu, J., \& Margono, G. (2017). The relationship between higher order thinking skills and academic performance of student in mathematics instruction. International Education Studies; 10(11), 78-85.

Thompson, T. (2008). Mathematics teachers' interpretation of higher-order thinking in Bloom's taxonomy. International Electronic Journal of Mathematics Education, 3(2), 96-109.

Vula, E., Avdyli, R., Berisha, V., Saqipi, B., \& Elezi, S. (2017). The impact of metacognitive strategies and self-regulating processes of solving math word problems. International Electronic Journal of Elementary Education, 10(1), 49-59.

Wilson, D. \& Conyers, M. (2016). Teaching students to drive their brains: Metacognitive strategies, activities, and lesson ideas. Alexandria, VA: ASCD.

Yen, T.S. \& Halili, S.H. (2015). Effective teaching of higher-order thinking (HOT) in education. The Online Journal of Distance Education and e-Learning, 3(2), 41-47. 